\title{
(- OPEN ACCESS \\ Concurrent mechanical haemolytic anaemia and heparin-induced thrombocytopenia following transcatheter aortic valve replacement
}

\author{
Nathan W Furukawa, ${ }^{1}$ Fernando M Jumalon, ${ }^{1}$ Daniel B Friedman, ${ }^{2}$ Linda R Kelly ${ }^{3}$
}

Adult Inpatient Medical

Services, Presbyterian Hospital, Albuquerque, New Mexico, USA ${ }^{2}$ Presbyterian Heart Group, Presbyterian Hospital, Albuquerque, New Mexico, USA ${ }^{3}$ Department of Pharmacy, Presbyterian Hospital, Albuquerque, New Mexico, USA

\section{Correspondence to} Dr Nathan W Furukawa, furukawa1@gmail.com

Accepted 30 September 2018

\section{SUMMARY}

A 78-year-old man with a history of severe aortic stenosis presented with confusion, irregular behaviour and dyspnoea 8 days following transcatheter aortic valve replacement. His exam was consistent with a heart failure exacerbation and he had elevated aminotransferases, bilirubin and prothrombin time suggestive of shock liver. A CT head scan demonstrated a subacute large left temporoparietal infarction. His aminotransferase and prothrombin time levels normalised with diuresis, but his indirect bilirubin remained elevated and he developed anaemia and thrombocytopenia consistent with a haemolytic anaemia. A transthoracic echocardiogram demonstrated a paravalvular leak. His thrombocytopenia continued to worsen prompting testing for antibodies against heparinPF4 complexes which was positive. A serotonin release assay later returned positive, confirming the diagnosis of heparin-induced thrombocytopenia. This case illustrates that the presence of haemolytic anaemia does not

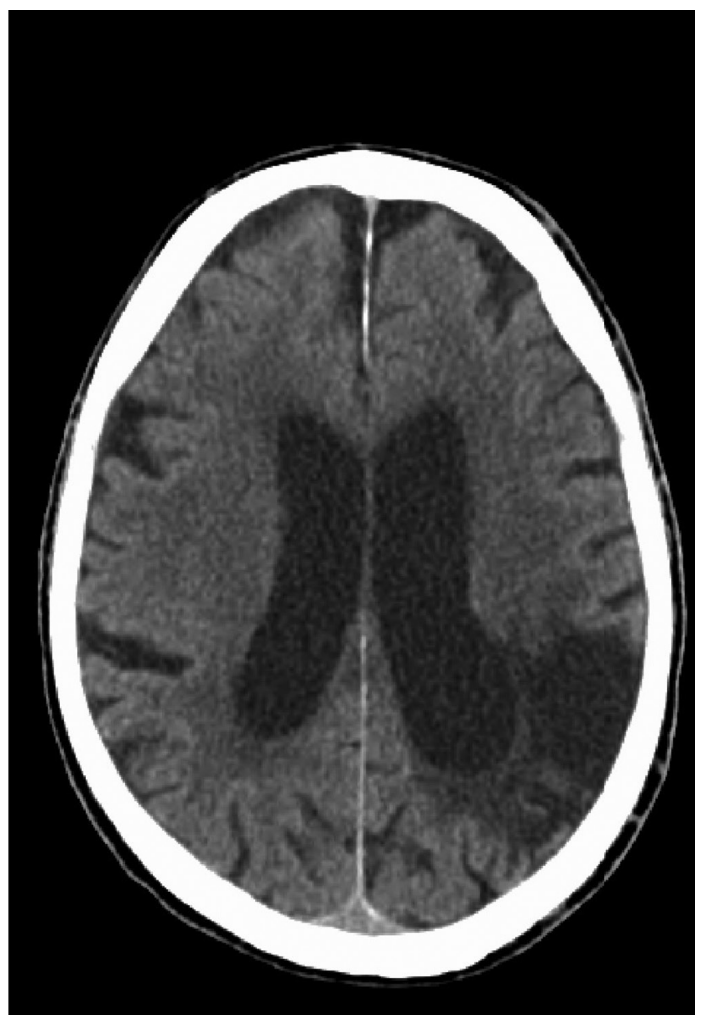

Figure 1 CT scan of the head demonstrating a subacute large left temporoparietal infarction. necessarily exclude other causes of thrombocytopenia that may occur concurrently.

\section{BACKGROUND}

Since the approval of transcatheter aortic valve replacement (TAVR) in high surgical risk patients unable to undergo surgical aortic valve replacement in 2011, the procedure has been increasingly performed in intermediate-risk to high-risk surgical populations. ${ }^{1-3}$ While TAVR has been shown to be non-inferior to surgical aortic valve replacement in this group, the risks of complications are different and include arterial access injuries (25\%), valve deployment complications such as paravalvular leak (PVL) (mild 38\%, moderate/severe 9.1\%) and postprocedural stroke (1.5\%-4.3\%). ${ }^{3-5}$ Haematological complications following TAVR are common with as many as $15 \%$ of patients developing haemolysis and $35 \%$ of patients developing thrombocytopenia. ${ }^{6} 7$ The mechanism behind haemolysis and thrombocytopenia is related to shear stress introduced by the artificial valve and can be worsened if a PVL is present. ${ }^{4}$ The degree of haemolysis or thrombocytopenia is usually minimal and resolves in a majority of patients shortly after TAVR. ${ }^{5-7}$ However, the presence of severe thrombocytopenia or PVL has been associated with worse outcomes. ${ }^{5-7}$

A rare cause of a thrombocytopenia is heparin-induced thrombocytopenia (HIT) which requires an initial exposure to heparin that produces pathogenic antibodies to heparin/PF4 complexes. ${ }^{8}$ Subsequent exposure to heparin results in the binding of FcyRIIA on platelets and monocytes leading to platelet activation, a hypercoagulable state and oftentimes life-threatening thrombosis. ${ }^{89}$ Treatment involves eliminating exposure to heparin products and anticoagulation with non-heparin anticoagulants. Delays in diagnosis and treatment are common due to a lack of recognition of suspected HIT cases, particularly in instances where a concomitant cause of haemolysis is present. While the risk of developing HIT after TAVR is rare $(0.5 \%)$, it is associated with longer hospitalisation, higher costs and higher rates of mortality. ${ }^{10}$ We report a patient who developed haemolysis and thrombocytopenia following TAVR who was subsequently found to have both mechanical haemolysis from a PVL and severe thrombocytopenia from HIT. 


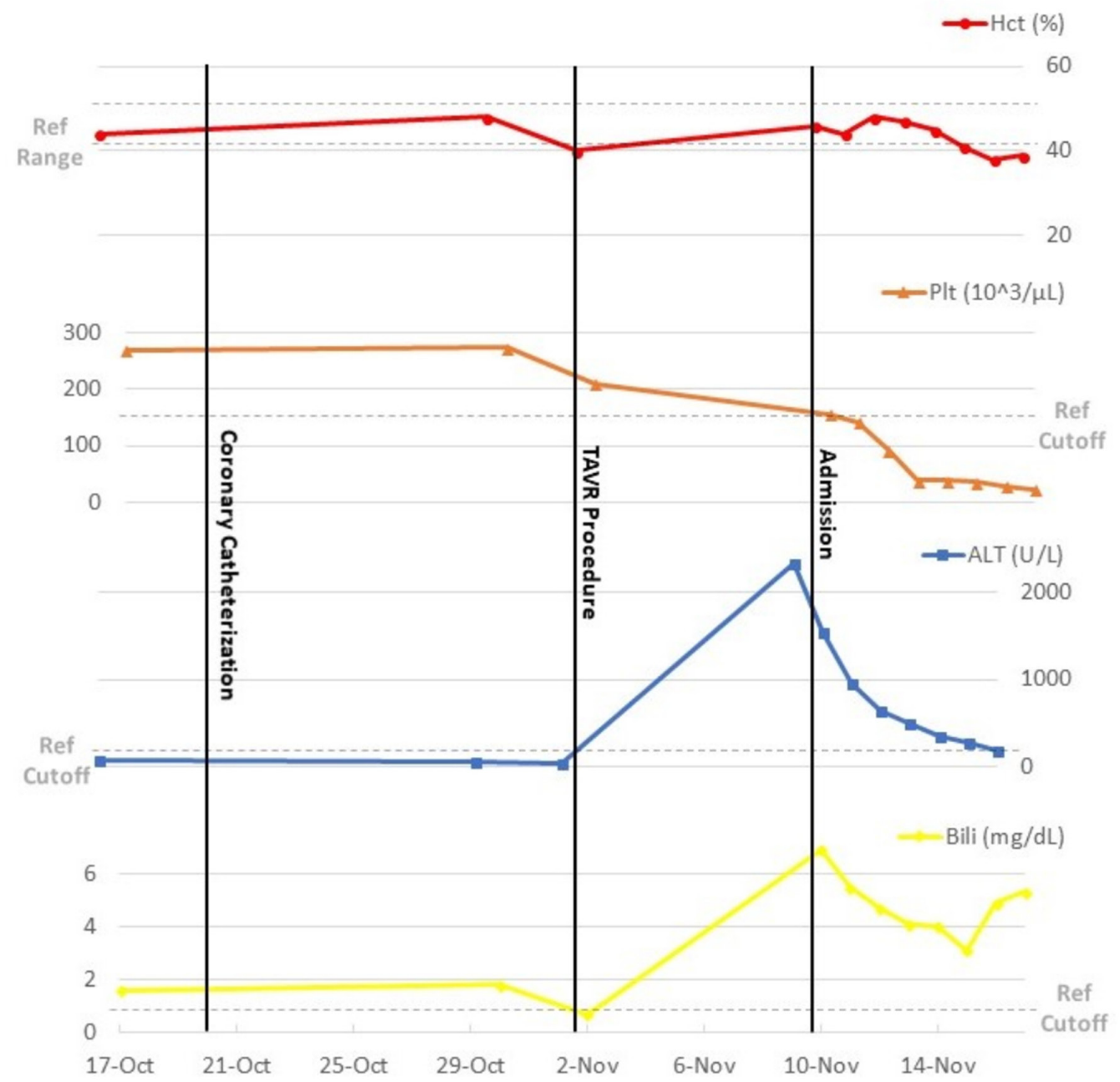

Figure 2 Haematocrit, platelets, alanine aminotransferase and bilirubin trend in relation to coronary catheterisation and transcatheter aortic valve replacement.

\section{CASE PRESENTATION}

A 78-year-old man presented to his primary care physician with right groin pain and was diagnosed with an inguinal hernia. As part of his evaluation, he was noted to have a harsh late systolic murmur grade V/VI murmur with radiation to the carotids. This prompted an echocardiogram which revealed a severely calcified aortic valve (valve area $0.60 \mathrm{~cm}^{2}$, mean gradient $23 \mathrm{~mm} \mathrm{Hg}$, Left ventricular outflow tract/aortic valve velocity ratio 0.18 ) and a left ventricular ejection fraction of $15 \%$ with global hypokinesis, consistent with low-flow low-gradient severe aortic stenosis. Notably, the patient had been very physically active playing tennis, riding his bicycle and doing vigorous yard workup until the prior month when he became increasing fatigued and short of breath with activity.

He was referred to a cardiologist and underwent coronary angiography which demonstrated mild non-obstructive coronary artery disease. He was seen by a cardiovascular surgeon who deemed he was a better candidate for TAVR given his age, history of remote stroke and depressed left ventricular function. He ultimately underwent TAVR with a $26 \mathrm{~mm}$ Edwards SAPIEN 3 pericardial tissue valve using a left femoral artery approach. A large degree of calcification of the valve was noted intraoperatively. Valvuloplasty prior to TAVR was not performed and post-implantation his valve was noted to be well positioned and not obstructing a coronary ostium. His post-TAVR echocardiogram demonstrated reduction in his mean aortic gradient from
23 to $7 \mathrm{~mm} \mathrm{Hg}$ and a mild PVL. The remainder of his hospital course was uneventful, and he was discharged 2 days after TAVR placement on aspirin and warfarin for routine post-TAVR stroke prevention. His international normalised ratio (INR) at time of discharge was 1.2 .

Three days following TAVR placement, his family noted that he became acutely confused, labile and impulsive. Over the ensuing week, he became increasingly short of breath and developed abdominal swelling and jaundice. On the day of admission, he developed acute dyspnoea and was noted to be tachycardic and hypotensive, ultimately leading to him being admitted to the hospital.

\section{INVESTIGATIONS}

On physical examination, the patient was oriented only to himself, had a Glasgow Coma Score of 13, but no focal extremity weakness. He had bibasilar diminished breath sounds with crackles, an elevated jugular venous distention to $12 \mathrm{~cm}$ and mild lower extremity oedema. He also had a large left inguinal haematoma. His labs were notable for haematocrit $46 \%$, platelets $15610^{3}$ / $\mu \mathrm{L}$, INR 5.7, troponin $0.227 \mathrm{ng} / \mathrm{mL}$ (normal $<0.060 \mathrm{ng} / \mathrm{mL}$ ), creatinine $1.53 \mathrm{mg} / \mathrm{dL}$, brain natriuretic peptide $12445 \mathrm{pg} / \mathrm{mL}$ (normal $<450 \mathrm{pg} / \mathrm{mL}$ ), aspartate aminotransferase $1914 \mathrm{U} / \mathrm{L}$, alanine aminotransferase $2316 \mathrm{U} / \mathrm{L}$ and total bilirubin $6.9 \mathrm{mg} / \mathrm{dL}$. 
An ECG demonstrated sinus tachycardia with unchanged left bundle branch block. A chest radiograph demonstrated pulmonary interstitial oedema and cardiomegaly. CT scan of the pelvis with contrast demonstrated a $7.7 \mathrm{~cm}$ inguinal canal haematoma with active mild extravasation. CT of the head demonstrated a resolving large left middle cerebral artery temporoparietal remote infarction (figure 1).

His vitals, physical exam and lab findings were suggestive of heart failure exacerbation leading to shock liver. Hypotension from his inguinal haematoma was considered unlikely given his normal haematocrit and elevated volume status, and sepsis was less likely due an unremarkable white count, chest radiography and urinalysis. His subacute stroke was initially attributed to a potential thrombotic or calcium embolism post TAVR. However, antiplatelet and anticoagulation therapies were withheld due to his expanding inguinal haematoma.

He was started on aggressive diuresis with intravenous furosemide. After 3 days of diuresis, his shortness of breath resolved, his confusion improved and his aminotransferase levels, creatinine and INR normalised. During this time, however, his platelets drastically decreased from 156 to $3910^{3} / \mu \mathrm{L}$ and his labs were notable for a lactate dehydrogenase of $573 \mathrm{U} / \mathrm{L}$, haptoglobin of $11 \mathrm{mg} / \mathrm{dL}$, an elevated total bilirubin to $4.0 \mathrm{mg} / \mathrm{dL}$ with an indirect bilirubin of $3.0 \mathrm{mg} / \mathrm{dL}$ and a smear demonstrating schistocytes. Repeat echocardiogram demonstrated a functioning TAVR with unchanged mild PVL. Thrombotic thrombocytopenic purpura was considered but thought less likely in the absence of fever, improving renal function and a normal ADAMTS13 level. Similarly, disseminated intravascular coagulation was considered unlikely due to a normal creatinine, INR and fibrinogen. Therefore, the haemolysis and thrombocytopenia were initially attributed to shear forces from his PVL.

On review of the timing of the patient's thrombocytopenia, there was an acute platelet drop observed 10 days after his TAVR procedure which prompted concern for HIT (figure 2). Further chart review revealed that he had been first exposed to unfractionated heparin during coronary angiography 21 days prior to admission and then again during his TAVR placement 8 days prior to admission. His 4T score was 6 (2 points each for thrombocytopenia, timing and thrombosis), indicating a high probability of HIT. Empiric anticoagulation with non-heparin anticoagulants was initially withheld due to his groin haematoma and concerns for active extravasation. His HIT PF4 antibody enzyme immunoassay was resulted positive $1.78 \mathrm{OD}$ (normal $<0.300 \mathrm{OD}$ ).

\section{TREATMENT}

The patient was started on an argatroban infusion for prevention of further thrombosis. A subsequent confirmatory serotonin release assay was positive confirming the diagnosis of HIT.

\section{OUTCOME AND FOLLOW-UP}

The patient's mental status slightly improved, but on hospital day 6 he acutely developed atrial fibrillation with rapid ventricular response, increasing tachypnoea and hypotension. Chest radiograph demonstrated a new left lung base infiltrate concerning for aspiration related to dysphagia from his stroke. He was started on intravenous crystalloid infusion, broad-spectrum antibiotics and amiodarone but progressed to septic shock with multiorgan failure. After discussion with the patient's family about his prognosis, he was transitioned to comfort care and died in the presence of his loved ones.

\section{DISCUSSION}

In diagnostic medicine, there is constant tension between the desire to explain a constellation of clinical findings by a sole aetiology versus multiple overlapping aetiologies. These competing heuristics are colloquially referred to as Occam's razor and Hickam's dictum. ${ }^{11}$ Occam's razor refers to the theory that the simplest explanation unifying all of a patient's symptoms is often the right one, while Hickam's dictum introduces uncertainty by suggesting that the myriad of a patient's symptoms is often due to multiple diseases and their interactions with one another. Both heuristics are useful in searching for a unifying diagnosis while also being open to alternative explanations for the patient's underlying disease.

\section{Patient's perspective}

My husband worked as a painter and was an incredibly hard worker. Even when he retired, he remained very active. He played tennis like a demon three times a week. On the other days, he would ride his bike 60 miles, take long walks or work in the yard. He was always so strong, and it never dawned on me that he could be having heart problems.

In October, I noticed that he had a large hernia and we went to the doctor. I mentioned that my husband had been tired lately and cut his bike riding down to 40 miles. The doctor listened to his heart and said that there was something wrong. He then got an echo that showed he had aortic stenosis. He could not believe he was sick and thought they were making a mistake. But his mother died of congestive heart failure, so we were worried and listened to the doctor.

The surgeon gave us the choices of doing nothing, open heart surgery or TAVR. He said he might die during surgery, but assured us that he would be much better after the TAVR. So many things were going through our minds and I do not remember them talking about the risks. We trusted the doctors and decided to go along with TAVR.

Shortly after discharge home from the TAVR procedure, I found my husband stumbling around and making strange remarks. He was wearing a shoe on one foot and a sock on the other foot. His sweatshirt was inside out and he was wearing a shirt on top of it backwards. He was disoriented and had trouble finding the bathroom. He then became short of breath, so I checked his blood pressure and it was 63/47 with a heart rate of 143. I took him to an urgent care clinic and then they sent him to the hospital.

In the hospital, my husband kept asking if he could go home, but I realistically could not take care of him. When the doctor told me that his platelet count had dropped to 20000 I knew something was wrong because his platelet count was 275000 when he saw primary doctor earlier. Then suddenly my husband became sicker. and we knew he was dying. Dr Furukawa and the nurses were fantastic and helped move us into a private room and comforted our family. All three of our sons were able to be with my husband when he took his last breath. We had 53 good years together.

To the doctors, nurses and staff that cared for my husband, I want to say thank you for making us feel welcome and valued, answering our questions in ways we could understand, and seeing my husband as the person he was. My hope for his story is that it might help students and doctors be more aware of HIT, diagnose it in other patients and maybe even save a life.

- Wife of the deceased 
Learning points

- Paravalvular leak is a frequent complication of transcatheter valve replacement and can cause haemolysis and thrombocytopenia due to shear forces.

- Patients with haemolytic anaemia and thrombocytopenia can have distinct causes of haemolysis and low platelets.

- The treatment for heparin-induced thrombocytopenia is anticoagulation with non-heparin anticoagulants to prevent new thrombosis and should be started whenever there is suspicion for heparin-induced thrombocytopenia provided there is no clear contraindication.

In this case, our patient's clinical presentation with subacute stroke and heart failure exacerbation after TAVR was consistent with known and commonly observed complications of the procedure. ${ }^{3}$ Haemolysis and thrombocytopenia are similarly known complications of TAVR and PVL. ${ }^{67}$ However, the degree of severe thrombocytopenia relative to mild haemolysis prompted further workup for causes of pure thrombocytopenia which ultimately yielded the diagnosis of HIT. Since the onset of the stroke occurred $>24$ hours after his TAVR procedure, it was less likely to be related to an intraoperative calcification embolisation. In this case, the patient's stroke was likely triggered by hypercoagulability due to HIT. Because the thrombocytopenia developed after just two doses of unfractionated heparin and was delayed by several days with no additional administration of heparin products, it is reasonable to categorise this as a case of delayed onset HIT. ${ }^{9}$ While the diagnosis of HIT was obscured by Occam's razor and attribution of his thrombocytopenia to PVL and shear forces, earlier diagnosis would likely not have changed his course since treating HIT with anticoagulation was initially contraindicated due to his expanding inguinal haematoma. However, earlier diagnosis in patients without a contraindication to anticoagulation would be beneficial as it would reduce the delay in initiation of non-heparin anticoagulation and reduce thrombotic complications. This case illustrates the importance of pursuing multiple diagnoses when a single diagnosis does not fully explain the clinical scenario.

Contributors NWF: patient care, consent, writing and submission. FMJ: institutional approval, writing and review. DBF: patient care, writing and review. LRK: patient care, writing and review.

Funding The authors have not declared a specific grant for this research from any funding agency in the public, commercial or not-for-profit sectors.

Competing interests None declared.

Patient consent Next of kin consent obtained.

Provenance and peer review Not commissioned; externally peer reviewed.

Open access This is an open access article distributed in accordance with the Creative Commons Attribution Non Commercial (CC BY-NC 4.0) license, which permits others to distribute, remix, adapt, build upon this work non-commercially, and license their derivative works on different terms, provided the original work is properly cited, appropriate credit is given, any changes made indicated, and the use is non-commercial. See: http://creativecommons.org/licenses/by-nc/4.0/.

\section{REFERENCES}

1 Smith CR, Leon MB, Mack MJ, et al. Transcatheter versus surgical aortic-valve replacement in high-risk patients. N Engl J Med 2011;364:2187-98.

2 Leon MB, Smith CR, Mack MJ, et al. Transcatheter or surgical aortic-valve replacement in intermediate-risk patients. N Engl J Med 2016;374:1609-20.

3 Vahl TP, Kodali SK, Leon MB. Transcatheter aortic valve replacement 2016: a modernday through the looking-glass adventure. J Am Coll Cardiol 2016;67:1472-87.

4 Dencker D, Taudorf M, Luk NH, et al. Frequency and Effect of Access-Related Vascular Injury and Subsequent Vascular Intervention After Transcatheter Aortic Valve Replacement. Am J Cardiol 2016:118:1244-50.

5 Généreux P, Head SJ, Hahn R, et al. Paravalvular leak after transcatheter aortic valve replacement: the new Achilles' heel? A comprehensive review of the literature. J Am Coll Cardiol 2013;61:1125-36.

6 Laflamme J, Puri R, Urena M, et al. Incidence and risk factors of hemolysis after transcatheter aortic valve implantation with a balloon-expandable valve. Am J Cardiol 2015;115:1574-9.

7 Dvir D, Généreux P, Barbash IM, et al. Acquired thrombocytopenia after transcatheter aortic valve replacement: clinical correlates and association with outcomes. Eur Heart J 2014:35:2663-71.

8 Arepally GM. Heparin-induced thrombocytopenia. Blood 2017;129:2864-72.

9 Greinacher A, Selleng K, Warkentin TE. Autoimmune heparin-induced thrombocytopenia. J Thromb Haemost 2017;15:2099-114.

10 Telila T, Akintoye E, Ando T, et al. Incidence and outcomes of heparin-induced thrombocytopenia in patients undergoing transcatheter aortic valve replacement. Am J Cardiol 2017;120:300-3.

11 Mani N, Slevin N, Hudson A. What Three Wise Men have to say about diagnosis. BMJ 2011;343:d7769.

Copyright 2018 BMJ Publishing Group. All rights reserved. For permission to reuse any of this content visit

http://group.bmj.com/group/rights-licensing/permissions.

BMJ Case Report Fellows may re-use this article for personal use and teaching without any further permission.

Become a Fellow of BMJ Case Reports today and you can:

- Submit as many cases as you like

- Enjoy fast sympathetic peer review and rapid publication of accepted articles

- Access all the published articles

- Re-use any of the published material for personal use and teaching without further permission

For information on Institutional Fellowships contact consortiasales@bmjgroup.com

Visit casereports.bmj.com for more articles like this and to become a Fellow 